
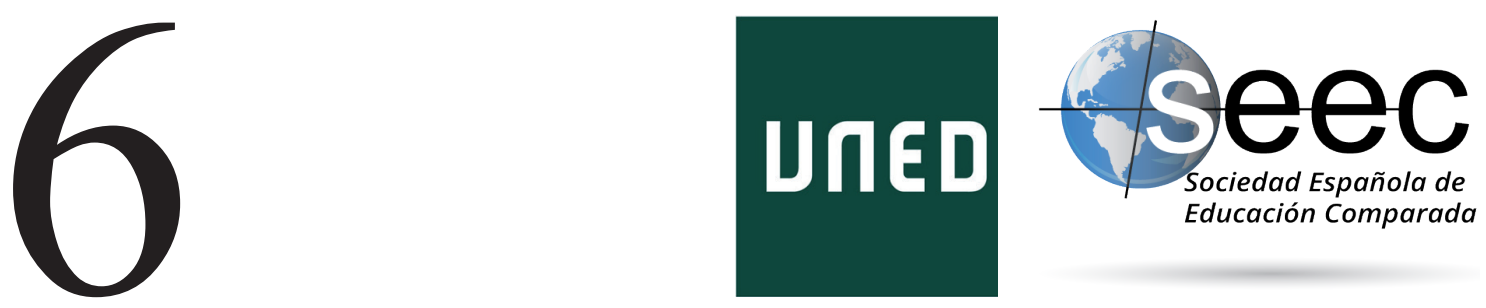

\title{
La metodología comparatista en los estudios literarios
}

Comparative methodology in literary studies

\section{Davide Mombelli*}

DOI: $10.5944 /$ reec.34.2019.24379

\author{
Recibido: 14 de mayo de 2019 \\ Aceptado: 26 de junio de 2019
}

\footnotetext{
* Davide Mombelli: Investigador de la Facultad de Filosofía y Letras I (Filología), de la Universidad de Alicante. Entre sus publicaciones (en colaboración) destacan obras como «La literatura española del siglo XVIII» (Instituto Juan Andrés de Comparatística y Globalización, 2017); «Napoli» (Casimiro, 2017); «La figura de la Tierra» (Casimiro, 2017). Datos de contacto: E-mail:davide.mombelli@ua.es
} 


\title{
Resumen
}

Es el presente artículo un primer ensayo de clasificación de los principales términos y conceptos relativos a la metodología de la Literatura comparada. Se organiza el material en tres diferentes secciones. En la primera se procede a unas breves aclaraciones terminológicas y conceptuales preliminares acerca del comparatismo y la Literatura comparada como disciplina. En la segunda parte se describe la primera operación comparatista, a saber, la inherente a la delimitación de los objetos a comparar. En la tercera y última parte se trata el modo de comparación en sus diferentes concreciones conceptuales y terminológicas. En nuestro análisis se han tenido en cuenta los principales manuales de Literatura comparada, así como otras obras teóricas acerca de la metodología, la teoría o la historia de la disciplina.

Palabras clave: Literatura comparada; Metodología; Modos de comparación; Objetos de comparación

\begin{abstract}
This article is a first essay of classification of the main terms and concepts related to the methodology of Comparative Literature. The material is organized in three different sections. In the first section we proceed to some brief terminological and conceptual preliminary clarifications about the Comparison and Comparative Literature as a discipline. The second part describes the first comparative operation, namely the one inherent to the delimitation of the objects to be compared. The third and final part deals with the mode of comparison in its different conceptual and terminological concretions. In our analysis we have taken into account the main manuals of Comparative Literature, as well as other theoretical works about the methodology, the theory or the history of the discipline.
\end{abstract}

Key Words: Comparative Literature; Methodology; Comparison modes; Comparison objects 


\section{El comparatismo y la literatura comparada}

Objeto del presente artículo es una presentación esquemática de los términos, nociones y conceptos relativos a la metodología de la Literatura comparada. Organizamos el material aquí comentado en dos secciones diferentes, de acuerdo con las dos operaciones fundamentales del comparatismo literario (la delimitación del objeto y el establecimiento del modo de comparación). Antes de proceder con nuestro análisis, es oportuno apuntar algunas breves aclaraciones terminológicas y conceptuales preliminares.

Se confunde, sobre todo en área francesa y anglosajona, la fundación universitaria de la disciplina, fechable en el último tercio del siglo XIX, con el establecimiento de la metodología comparatista misma, llegándose a afirmar que la Literatura comparada es una «invención» reciente y fundamentalmente francesa. Se percata prontamente de esta tergiversación Benedetto Croce, quien en 1903 escribe en las páginas de su revista $L a$ Critica un artículo titulado «La 'letteratura comparata'». Pretexto de este breve escrito es la publicación del prospecto del nuevo Journal of comparative Literature, fundado por G.E. Woodberry, J.B. Fletcher y J.E. Spingarn. Croce se pregunta qué es la Literatura comparada, apuntando tres diferentes definiciones.

En primer lugar, define como Literatura comparada esa forma de investigación que se sirve del método comparado. Sin embargo, siendo el método comparado un simple método de investigación, este no es suficiente para limitar un campo de estudios.

Una segunda definición se refiere directamente a la «tradición histórica» y se relaciona al concepto de Lingüística comparada: la Literatura comparada es una búsqueda de ideas o temas literarios con el fin de individuar alteraciones, asociaciones, desarrollos e influencias recíprocas en las distintas literaturas (Croce, 1966, p. 72)1. Objeto de trabajos de este tipo es la historia «externa» (la «tradición literaria») y no la verdadera génesis de la obra literaria. Falta, pues, el estudio del «momento creativo». Resultado de todo ello es esa «monstruosa dirección de la crítica» por la cual los eruditos investigadores de fuentes imaginan haber logrado la explicación de una obra literaria al haber determinado, quiméricamente, sus antecedentes literarios.

El tercer significado de la Literatura comparada: el que considera todos los antecedentes de la obra literaria, cercanos y lejanos, prácticos e ideales, filosóficos y literarios, traducidos en palabras o en formas plásticas y figurativas para los cuales la historia comparada es inseparable del concepto mismo de historia de la literatura. En este tercer significado, la historia comparada de la literatura es la historia entendida como explicación completa de la obra literaria (p. 75). En otros términos, Croce ya no ve la diferencia entre este tercer significado y la «Historia literaria» tout court, sin adjetivos.

En resumen, dejando de lado el primer significado por indeterminado, Croce sostiene que dos son los diferentes modos de entender la Historia literaria comparada: uno meramente literario-erudito y otro realmente histórico y explicativo, el cual contiene en sí el momento erudito, pero entendido en su totalidad y ya no como un simple fragmento aislado. El comparatismo literario, según Croce, es práctica propia de la historia literaria y no necesita pues una especificación disciplinaria. El filósofo italiano critica la disciplinarización de un método, el comparatista, llevada a cabo por cierta historiografía y crítica literaria contemporánea. Croce reivindica así la gran tradición comparatista europea moderna (Morhof, Herder, Lessing, Schlegel, Bouterweck), así como su origen clásico (el parangón grecolatino).

1 Hay traducción española completa del texto, por S. Chiapello, incluida en su artículo «Benedetto Croce y la primera cátedra de 'Literatura comparada'» (en Aullón de Haro, 2012, pp. 463-477). 
Croce, en su breve reseña-ensayo, revaloriza también la tradición comparatista italiana. Croce menciona en su discurso el De vulgari eloquentia de Dante como momento fundacional moderno del comparatismo lingüístico y literario y comienza su artículo con una referencia a la cátedra de Literatura comparada en la Universidad de Nápoles que Francesco De Sanctis, a la sazón ministro de Educación, creó en 1861 para Giorgio Herwegh, quien finalmente no pudo ocuparla, y que él mismo ocupó entre 1871 y 1876 (Chiapello, 2012). La institución de la cátedra en 1861 anticipa pues de casi cuarenta años la cátedra de la Universidad de Lyon (1897), considerada por muchos historiadores del comparatismo, sobre todo franceses, el acto fundacional de la disciplina. Cabe decir que Croce no recuerda, en su breve recorrido histórico, a Juan Andrés, autor por él conocido pero intencionadamente no citado por ser, según su planteamiento, exponente de cierta erudición dieciochesca. Sólo recientemente se ha demostrado el efectivo valor e importancia de Andrés en la construcción de la comparatística literaria moderna, gracias sobre todo a su Historia Universal de las Letras y las Ciencias (Origen, progresos y estado actual de toda la literatura) (Aullón de Haro, 1997; Aullón de Haro, García Gabaldón y Navarro Pastor, 2002).

Como recuerda Pedro Aullón de Haro, el comparatista es un método connatural a la epistemología de las Ciencias Humanas y las ciencias en general: en las ciencias literarias, el primer gran conceptualizador fue Dionisio de Halicarnaso. En la Epístola a Pompeyo Gémino, el filólogo helénico dice que «el mejor método de investigación es la comparación» (2001, pp. 221-246). De acuerdo con Aullón de Haro, podemos afirmar que:

«la Literatura comparada, de manera análoga a la Lingüística comparada, especifica un sector metodológico de la ciencia literaria y no define ni delimita una disciplina independiente o propiamente dicha de su serie sino un camino o método cuyo espacio en tanto que sector metodológico pluridisciplinario» (2012, p. 292).

Aullón de Haro insiste, como Croce y también Dilthey (1978), en determinar la comparación y el comparatismo como operaciones cognoscitivas y conceptos epistemológicos de valor universal. También sostiene que la idea de universalidad y su concreción en tanto que Literatura universal, o su posibilidad, «es requisito de toda teoría literaria comparatista, pues constituye no solo su requerible máximo y completud, mientras que su mínimo viene delimitado en la Literatura nacional, sino el modo lógico en que se sustenta» (2012, p. 305).

Por otra parte, téngase en cuenta la importancia del método comparatista en la hermenéutica, disciplina cuyo objeto es la interpretación de los textos, por lo que dicha metodología es inherente no solo a la Historia comparada de la literatura, sino también a la Crítica literaria (falaz sería, desde luego, deslindar los dos campos disciplinarios). En un reciente libro coordenado por Andreas Mauz y Hartmut von Saas se definen e ilustran las implicaciones hermenéuticas del método comparatista en relación no solo con la disciplina en sí sino con las demás áreas de las Ciencias Humanas (2011). De entre los trabajos más de corte teórico relativos a los fundamentos y metodología de la Literatura comparada, además del ya citado Metodologías comparatistas y Literatura comparada (2012), cabe mencionar también los volúmenes de Guy Jucquois (1989, 1991, 1993, 1994 y 2000 $)^{2}$ y el Handbuch Komparatistik. Theorien, Arbeitsfelder, Wissenspraxis editato por Rüdiger Zymner y Achim Hölter (2013). Recuérdese asimismo el capítulo de Pierre

2 Véase la exposición de la teoría comparatista de Jucquois realizada por Marta Núñez (en Aullón de Haro, 2012, pp. 242-251). 
Brunel titulado «El hecho comparatista» (en Brunel y Chevrel, 1994, pp. 21-50), así como la propuesta epistemológica de Jesús González Maestro y su acercamiento a la cuestión comparatística desde el punto de vista del Materialismo Filosófico como Teoría de la Literatura (2008).

Frente a estas posturas, Paul Van Tieghem, uno de los exponentes más relevantes de la conocida como «comparatística de las cátedras», es partidario de una concepción de la Literatura comparada como disciplina:

«La literatura comparada es considerada como una disciplina distinta, pero paralela a la historia particular de las diferentes literaturas. Sus métodos son, en parte, los mismos que los de la historia literaria nacional, en parte más especiales y adaptados a su peculiar tarea» (1931, p. 60).

La postura de Van Tieghem confirma cierta tendencia, sobre todo francesa, a determinar un campo disciplinario distinto e individualizado para la Literatura comparada, a fin de justificar académicamente, en cierta manera, la institución de cátedras universitarias.

\section{La delimitación del objeto: el establecimiento de las unidades}

Como decíamos, primera operación comparatista es la delimitación de los objetos a comparar. El establecimiento de los «términos de comparación» es una operación de carácter fundamentalmente epistemológico, puesto que todo comparatismo reside efectivamente en los 'términos de la comparación', es decir, en los elementos que son puestos en relación. En adelante, seguimos a Aullón de Haro y su tratamiento acerca del problema (Aullón de Haro, 2012, pp. 15 y ss.).

Los objetos delimitados, denominables con el marbete general de «entidades», pueden constituirse en términos mayores o menores. Los términos mayores se vinculan a los menores mediante una relación del todo con la parte o, en otros términos, mediante una conexión hiperónima. Los términos menores se subsumen, pues, en los mayores. Las entidades pueden definirse como «lugares» y pueden ser «extensivos», multiplicables. No necesariamente tienen que tener una existencia verbal. De acuerdo con este marco epistemológico general, pueden darse comparaciones entre la literatura y otros campos o esferas de la cultura, la ciencia o el arte. Ejemplos de entidades mayores son la Literatura, la Tradición, las Artes, las Religiones, las Ciencias o disciplinas científicas; ejemplos de entidades menores: un género literario o artístico, una serie de obras o una obra concreta, un estilo o técnica literaria o un concepto. En estos términos, se hace necesaria una impostación interdisciplinar y transversal de la metodología comparatista.

Se ha hablado, en los años 50 del pasado siglo, de una suerte de «crisis» de la Literatura comparada, sobre todo a partir de la disertación de René Wellek titulada precisamente «La crisis de la literatura comparada» (1958) (Wellek, 1968, pp. 11-220). La Literatura comparada, pese a su importancia académica, no ha sido capaz, según Wellek, de establecer un objeto diferenciado y una metodología específica. Según el crítico checo, síntomas de la crisis de la Literatura comparada serían una demarcación artificial del campo de estudios y de la metodología, un concepto mecanicista de los orígenes y de las influencias y una motivación en virtud de un nacionalismo cultural, tendencias provechosas pero imprecisas o falaces en algunos casos. Wellek propone, por lo tanto, la eliminación de la 
demarcación artificial que separa la Literatura comparada de la Literatura general: «lo que importa es el concepto de la investigación literaria como una disciplina unificada desembarazada de las restricciones lingüísticas» (p. 217). Wellek defiende una especie de «salto ontológico» entre la psicología del autor y una obra de arte, lo cual lo distancia de ciertas posturas «idealistas» o psicologistas. Opta, pues, por un estudio «intrínseco» de la obra, aunque destaca el peligro de caer en un simple «formalismo». Obra de arte sería, en última instancia, una «estratificada estructura de signos y significados», un concepto bastante difuso de «estructura» con el cual pretende superar la dualidad forma-contenido. Wellek escinde los componentes de la obra literaria en sus diferentes niveles, para luego pretender un estudio totalizante del objeto, el cual viene a ser una «totalidad diversificada», una «estructura de señales que, no obstante, implica y requiere significados y valores». Con esta definición pretende esquivar una falacia que se impone inevitablemente: la suma de las partes no da como resultado el todo.

Interviene en el debate surgido en esa época también Henry H.H. Remak con el estudio "Comparative Literature: Its Definition and Function" (1961, y reed. En 1971). Según Remak, el fin de la Literatura comparada es la comprensión de la literatura como un todo, lo cual implica relacionar también la literatura con otras esferas del conocimiento y de la actividad humana, en particular con los campos artísticos e ideológicos. Esta concepción de la Literatura comparada en su sentido «supradisciplinar» o «interastítico» es típica de cierto comparatismo anglosajón, principalmente norteamericano, y su praxis se incrementa a partir precisamente de los años 60 del pasado siglo. A pesar de que algunos teóricos como el mismo Remak incidieron sobre la novedad del enfoque metodológico, este no es en absoluto una novedad, sino que tiene una tradición antigua que, en el caso de la relación literatura-artes plásticas, puede retrotraerse a los mismos textos homéricos y a la descripción del Escudo de Aquiles, ejemplo insuperable de écfrasis. En época moderna, el libro paradigmático, además de las Reflexiones críticas sobre la poesía y la pintura de Jean Baptiste Dubos, es sin duda el Laocoonte de Lessing.

Ahora bien, volviendo a la cuestión del deslinde de las entidades u objetos de comparación, cabe decir que cualquier categoría literaria es susceptible de objetualizarse como entidad comparable. Sin duda, la «literatura» y la «obra literaria» ha de entenderse como la entidad más productiva y extensa dentro del universo comparatista. En efecto, a fin de permanecer dentro del campo metodológico y epistemológico de la Literatura comparada, es necesario que al menos uno de los dos términos de comparación sea una obra literaria.

Lo que podríamos definir el CRITERIO LITERARIO puede ser objeto de dos diferentes tratamientos: uno estrictamente empírico, por lo que se daría la serie literatura nacional / supranacional / universal; y otro teórico-metodológico (literatura nacional / comparada / general, según la propuesta de Van Tieghem). En ambos casos se hace necesario el establecimiento del "grado» (de menor a mayor extensión), el cual determina también la «distancia», que es la virtualidad comparativa esencial (a mayor grado de distancia, mayor virtualidad; así como la constitución de tres ejes: (1) el histórico o temporal; (2) el geográfico o espacial-cultural; (3) el entitativo o de naturaleza (Aullón de Haro, 2012, pp. 291 y ss.).

Ahora bien, antes de acotar el objeto literario y, por así decir, «adjetivarlo» (que es decir: especificarlo), hay que establecer previamente una definición de «literatura», operación epistemológica harto compleja (Aullón de Haro, 2016). Es conocido como el concepto de «literatura» cambia radicalmente a partir de la época romántica, cuando se 
acota a las Bellas Letras, siendo antes sinónimo de «cultura escrita»: así lo era para Juan Andrés, el ideador de la Historia de la Literatura universal de las letras y las ciencias. Curiosamente, en los estudios más recientes de Literatura comparada, asistimos a una nueva ampliación de los límites semánticos del término, en un período de auge de los conocidos como Cultural studies y los «Estudios postcolonialistas» o «multiculturalistas», siendo quizás el libro de Edward Said, Orientalism (1978), el ejemplo más significativo. Sin embargo, la concepción de «cultura» propia de estos enfoques relativamente recientes no coincide con la concepción de «cultura» ilustrada, puesto que se ha asistido en los últimos años a una progresiva devaluación del objeto de estudio respondiente a una injustificada delimitación del mismo que prescinde de factores fundamentales como el de «valor» o «interés» artístico o científico.

Entre lo nacional y lo universal se pueden establecer grados diferentes de supranacionalidad: es el caso de la literatura románica o Romanística, la Literatura asiática, árabe, mediterránea (recuérdese De la littérature du midi de l'Europe de Sismondi) o europea. Es esta última especificación la que más estudios ha generado en el marco del comparatismo del viejo continente (Chevrel, 1994, pp. 347-373).

Ernest Robert Curtius, en su conocida investigación Literatura europea y Edad Media latina, apunta un tan certero como desalentador diagnóstico:

«la moderna ciencia de la literatura - la de los últimos cincuenta años [el texto de Curtius se publica en 1948] - es un fantasma; es incapaz de examinar científicamente la literatura europea, y esto por dos razones: el estrechamiento arbitrario del campo de observación y el desconocimiento de la estructura autónoma de la literatura» (2004, p. 30).

Si bien la fundamentación moderna de esta idea nace sustancialmente en la Ilustración, será solo en pleno siglo XIX, tras las experiencias de Goethe (autor del afortunado concepto de Weltliteratur), Novalis, Herder, Schlegel y la fundación de la Romanística (Friedrich Christian Diez) cuando la Literatura Europea sea considerada como una unidad de sentido (Marino, 1998), en relación dialéctica con el concepto de Literatura Universal (la fijación terminología Universal-Europea permanece a menudo ambigua hasta el siglo XX). Europeístas fueron, además del antecitado Curtius, la mayoría de los grandes comparatistas de la primera mitad del siglo XX: Paul Hazard, Auerbach, Van Tieghem, Mario Praz, entre otros.

A partir de los años 80 del pasado siglo, los comparatistas en literatura comienza a hablar con más frecuencia de "nuevo paradigma», una expresión vinculada a otro concepto que en esos años se iba cada vez más apuntalando, a saber, el de SISTEMA (Pageaux, 1994, pp. 135-143; Swiggers, 1989, pp. 345-352). Recuerda Swiggers que el concepto de «sistema» adoptado por los teóricos del «nuevo paradigma» debe mucho al círculo de Praga y a la noción de «función» (Jakobson), así como a la teoría de Dionýz Ďurišin, quien en 1972 había propuesto una tipología sistemática de las relaciones literarias y había segregado el estudio de los contactos genéticos de las relaciones de solidaridad tipológica (Swiggers: 1998); no se olvide, sin embargo, como reconocen Itamar Even-Zohar (quien desarrolló una teoría de los «polisistemas», 1978) y Steven Tötösy de Zepetnec, que el concepto de «sistema literario» se debe fundamentalmente a Tynianov («Sobre la evolución literaria», 1927). Según Ďurišin la Literatura comparada no estudia las relaciones entre autores y entre obras, sino entre sistemas y subsistemas gobernados por normas y tendencias. Su objetivo no es describir estas relaciones 
sino explicarlas dentro del sistema de comunicación y de un aparato ideológico estratificado (1968, pp. 47-58).

Se define «sistema literario» la red de relaciones entre una cierta cantidad de actividades llamadas «literarias», y consiguientemente esas actividades mismas observadas a través de esta red. El sistema pretende englobar todos los aspectos, incluso los económicos, que gravitan en torno al hecho literario. Pese a esta declarada intención universalizante, la teoría sistemática de la literatura no deja de ser una sociologización del estudio literario, fundando en una concepción estrictamente estructuralista.

D.W. Fokkema, en su ensayo «La literatura comparada y el nuevo paradigma» publicado en 1982, afirma que el nuevo paradigma consiste en una nueva concepción del objeto de la investigación literaria (1998, pp. 149-172). Se abandona la exclusividad del texto literario como objeto único del estudio de la literatura ${ }^{3}$, siendo el nuevo objeto la «situación de la comunicación literaria» y el código literario empleado, es decir, las convenciones que han guiado la producción y recepción de textos que bajo ciertas condiciones han sido aceptados como literatura. La comparación, en última instancia, no sería entre obras artísticas y literarias, sino entre «códigos literarios» y el objetivo último es describir la sucesión de los sistemas literarios. Este nuevo planteamiento implica una evidente indeterminación a la hora de delimitar las entidades y los objetos de estudio. P. Swiggers, en «La innovación metodológica en el estudio comparativo de la literatura», publicado también en 1982, afirma que axioma del nuevo paradigma es una concepción de la Literatura comparada como el estudio de las relaciones jerárquicas entre metatextos translingüísticos

La comparación de sistemas o polisistemas literarios, de base estructuralista, ha tenido un auge en los años 80 y 90 del pasado siglo. Han de ponerse en duda, sin embargo, los efectivos logros de este planteamiento teórico-literario y su efectiva rentabilidad en la praxis de la crítica y del comparatismo literarios.

Otra de las entidades «mayores» de más relevancia para la Literatura comparada es TRADICIÓN. Si se considera su etimología, «tradición» implica «transmisión» (traditio, tradere), y tiene una dimensión que cruza varios ámbitos temáticos o disciplinarios. La tradición es un fenómeno de transmisión cultural caracterizado por la continuidad, pervivencia, perpetuación de una serie de «constantes». Lejos de hacerlo coincidir con el academicismo, es, además, un fenómeno «vivo», dialogante.

Según el gran historiador y comparatista Ernst Robert Curtius, es posible establecer unas constantes en la literatura europea. A la acepción de «continuidad» y «constante» de la tradición apelan también otros dos grandes pensadores de finales del XIX y comienzos del XX: Aby Warburg y Carl Gustav Jung. Warburg estudió la supervivencia de los estereotipos figurativos paganos en los nuevos ciclos de la cultura occidental en obras como El renacimiento del paganismo (ed. esp. 2005) o el gran proyecto del Atlas Mnemosyne (ed. esp. 2010), una colección de imágenes, grabados, iconos, etc. mediante la cual quiso Warburg relatar la memoria europea. Por su parte, Jung investigó las imágenes arcaicas originarias y permanentes del inconsciente colectivo (ed. esp. 1999) ${ }^{4}$.

Han escrito sobre el concepto de tradición, entre otros, Eric Hobsbawm y Terence Ranger (2002), Gilbert Highet (1954, conceptualizador de la categoría de «tradición

3 Relacionado con el concepto de sistema es la noción de «texto» y su «apertura» semiótica y cultural, conceptualizado, entre otros, por Yuri Lotman, Julia Kristeva o Cesare Segre.

4 Véase sobre todo el capítulo «Sobre las relaciones de la psicología analítica con la obra de arte poética» (1922) y «Psicología y poesía» (1930). Éste último se recoge también en el volumen colectivo editado por Ermatinger (1984, pp. 335-352). 
clásica»), T.S. Eliot (1980, pp. 13-23) según el poeta ingles, la tradición es simultánea y relacional, puesto que ningún poeta posee la totalidad de su propio significado), H.G. Gadamer (ed. esp. 1996-1998).

En cuanto a los «términos menores», como hemos recordado anteriormente, toda categoría literaria puede convertirse en objeto de comparación. Sin embargo, existe una serie de «entidades instrumentales» que permite parcelar el objeto en unidades más acotadas, mediante las cuales es posible caracterizar los componentes de las entidades mayores antes descritas. Es posible determinar pues dos series de términos menores: una se refiere al material contenutístico y otra que hace referencia a aspectos «formales». De la primera serie distinguimos los componentes fundamentales, a saber, topos, schema, símbolo, tema e imagen.

- El TóPICo es argumento retórico, concretamente perteneciente a la primera operación de la inventio, por lo que se refiere a la tradición clásica. Ersnt Curtius en Literatura europea en Edad Media latina propone una reactualización del tópico para la crítica y la historia de la literatura, interpretándolo como «constante» o permanencia temporal; por otra parte, Lausberg, en su conocido Manual de retórica literaria entiende entiende el tópico en tanto que un esquema ideológico; mientras que Jung, en su teoría psicológica, define el tópico en cuanto elemento arquetípico que se refiere al consciente colectivo cultural.

- Schema e imagen son categorías propias de la crítica artística. La definición de schema, también término de la retórica clásica referido al ámbito técnico del ornatus, ha sido teorizado en el siglo XX por Aby Warburg (Didi-Huberman, p. 2009): los schemata son elementos visuales mediante los cuales se hace posible una organización de la percepción.

En cuanto a la «imagen», su estudio se consolida gracias a la labor teórica y crítica de la escuela de Warburg. Cabe mencionar por su relevancia a Erwin Panofsky, quien publica en 1932 un ensayo titulado «Zum Problem der Beschreibung und Inhaltsdeutung von Werken der bildenden Kunst», finalmente reelaborado como introducción a sus Estudios sobre iconología (ed. esp. 1976).

Ahora bien, el concepto de «imagen» ha tenido una significación categorial para la Literatura comparada. En el ámbito estricto del comparatismo literario, «la imagen es una representación individual o colectiva en la que entran a la vez elementos intelectuales y afectivos, objetivos y subjetivos» (Pichois y Rousseau, 1967, p. 101). La imagen como «representación» del carácter y psicología de una literatura o cultura se ubica en la encrucijada entre literatura, sociología, historia política y antropología étnica. De ahí que se ha institucionalizado, en los años 60 del pasado siglo, una corriente de la Literatura comparada conocida con el nombre de Imagología. Uno de los autores más importantes es el comparatista francés Daniel-Henri Pageaux, autor en 1971 de un paradigmático estudio sobre las Images du Portugal dans les lettres françaises (1700-1755) (1971).

Por imagología se entiende «el estudio de las imágenes, de los prejuicios, de los clichés, de los estereotipos y, en general, de las opinoines sobre otros pueblos y culturas que la literatura transmite, desde el convencimiento de que estas images, tal y como se definen comúnmente, tienen una importancia que va más allá del puro dato literario o del estudio de las ideas y de la imaginación artística de un autor» (Moll, 2002, p. 349). En cierto modo vinculada a la imagología es también la mitocrítica y el estudio del mito: recuérdese los nombres de, entre otros, Claude Lévi-Strauss, Mircea Eliade o Gilbert Durand: imaginario de los hombres. Antecedente imprescindible es Giambattista Vico, 
quien en su Scienza nuova conceptualiza la categoría historiográfica de los «universales poéticos». Relacionado a su vez con el mito y la alegoría, el símbolo es, desde luego, concepto relevante en el marco literario del comparatismo; véase a propósito el imprescindible estudio de Cassirer y su teoría de la forma simbólica (ed. esp. 1998).

- El TEMA, y la serie «tema-motivo-materia», son categorías de gran relevancia metodológica para la Literatura comparada. La disciplina encargada de la definición y clasificación de los temas es la Tematología, la cual describe el campo metodológico de aquellas investigaciones comparatistas que investigan los aspectos temáticos que crean una tradición y los elementos formales de la literatura. Para una introducción breve pero precisa al argumento, remitimos a Manfred Beller (1984, pp. 101-133)5. Éste afirma que «la amplitud de significación del concepto de tema va, según la ubicación estéticoliterario, desde los presupuestos extra o preliterarios, pasando por la comprobación del contenido, hasta la interpretación del contenido de las obras poéticas» (p. 101).

- Restringidos específicamente al ámbito literario son los TIPOS o PERSONAJEs: es la narratología la subdisciplina teórico-crítica que se encarga de su definición. Tipos importantes en la historia de la literatura europea son, entre otros, el Don Juan, el héroe romántico (personificado por el Werther goethiano), el Fausto, el antihéroe (Don Quijote) etc. Si bien existen muchos ensayos sobre figuras o tipos concretos, no existe todavía una Teoría general del personaje. Véase a tal propósito los estudios de Aullón de Haro (2001) o Giacomo Debenedetti (1970).

Las aquí comentadas son concreciones terminológicas que, sin embargo, no definen un contenido conceptual con límites semánticos bien marcados: recuerda a propósito Beller que

«existe un innegable acuerdo fundamental sobre la influencia y efecto recíproco de las ideas, materias y motivos generales así como de las imágenes, topoi y estructuras específicas; (...) una investigación de temas más reciente, más general e internacional incluye también la investigación de los símbolos y la de los elementos formales de la tópica, la emblemática, la alegórica y la metafórica» (p. 103).

En cuanto a los términos menores de carácter más bien «formal», las entidades más relevantes son:

- Los GÉNERos LITERARIos. Todos los manuales más divulgados dedican un apartado al argumento. Véase, por ejemplo, el capítulo de Willy R. Berger, «Teoría de los géneros e investigación comparada de los géneros» (Berger, 1984, pp. 135-168); «Los géneros» en M.F. Guyard (1957, pp. 48-52); «Los géneros literarios» en C. Pichois y A. M. Rousseau (1967, pp. 111-115); «Formes, genres, modèles» en D.H. Pageaux (1994, pp. 113-130); «Poética comparada» de Jean Louis Backes (1994, pp. 51-70). El problema genérico es quizás el más complejo y a menudo su exposición en la manualística resulta cuanto menos parcial. Véase a tal propósito el tratamiento teórico realizado por Aullón de Haro, en particular sobre la cuestión de los géneros ensayísticos (1992; 2016).

En la praxis historiográfica o crítica, adquiere un sentido propiamente comparatista la investigación que estudia la recepción de géneros o formas métricas propios de una literatura nacional o regional en otra literatura, así el Leid o el Jaiku en España, por ejemplo. De ahí que la MÉTRICA sea otro factor muy relevante. Véase la síntesis

5 Véase también Pichois y Rousseau (1967, pp. 167-177); Guyard (1957, pp. 53-62); Pageaux (1994, pp. 77-94); Chardin (1994, pp. 132-147). 
conceptual e historiográfica que propone María Victoria Utrera en «Métrica comparada» (2012, pp. 379-394).

- El ESTILO es término técnico propio de la crítica y la estética literaria y conjuga factores y elementos formales a otros contenutísticos. El estilo literario es objeto de estudio de la Estilística, disciplina que tuvo un importante desarrollo en España (Dámaso y Amado Alonso, Carlos Bousoño). Josef Nadler, en su estudio titulado «El problema de la Historia del estilo» (1984, pp. 401-425), define el estilo como principium individuationis: «es, desde el punto de vista del creador, el organismo - no una mera suma- de medios individuales que permiten hacer visible y audible un algo espiritual y particularizar un algo general. Y, desde el punto de vista del investigador, el conjunto orgánico de los indicios partiendo de los cuales cabe inferir lo espiritual, lo actuante y lo general» (p. 404). Para determinar un estilo concreto es necesario recurrir al método comparatista, puesto que un estilo no puede llegar nunca a conocerse más que por contraste con otro algo individual. El estilo se hace visible cuando se contrapone un hombre a otro, una sociedad a una sociedad, un paisaje a otro paisaje, un pueblo a otro pueblo (Wölfflin definió los rasgos característicos del estilo barroco por contraste con los del estilo clásico). Se ha estudiado el Petrarquismo en Inglaterra o en España, el Gongorismo en Alemania, el Decadentismo en la literatura europea, etc.

\section{Los modos de la comparación}

En cuanto a los modos de relación, recuerda Aullón de Haro que dos son, fundamentalmente, las modalidades relacionales: (1) de facto (relación efectiva, documentalmente comprobable) o (2) por analogía. Son estos «modos como procedimientos operacionales» en su significado más general (Aullón de Haro, 2012, p. 303). Los modos de relación se concretan luego en una serie de modalidades específicas, que determinan el punto de vista a través del cual se estudia una conexión entre dos objetos que presentan cierta afinidad inicial, sea analógica o factual.

- RELACIÓn es término neutro y se suele emplear para determinar cualquier tipo de conexión o vínculo entre dos o más objetos de estudio (Aldridge, p. 1969). La fórmula clásica del comparatismo literario es X e Y (un ejemplo significativo: Erasmo y España de Bataillon) o X en Y (paradigma de este segundo esquema puede considerarse Goethe en France de Baldensperger de 1904, aunque cabe recordar el decisivo antecedente de Menéndez Pelayo, Horacio en España, 1885) (Pichois y Rousseau, 1967, pp. 96-100: «La fórmula X e Y»). Yves Chevrel propone una clasificación de las fórmulas usadas para describir las relaciones literarias, estableciendo una serie de categorías:

«1. Categoría cera "X e Y". Las dos incógnitas pueden designar, a elección, obras, escritores, países.

2. Categoría de tipo neutro "X en (el país) Y": "conocimiento de X por Y", "presencia de $\mathrm{X}$ en $\mathrm{Y}$ ”, "acogida de $\mathrm{X}$ por $\mathrm{Y}$ ”.

3. Categoría que ilustra la acción de "X": fortuna, éxito, reputación, irradiación, difusión, impacto, influencia.

4. Categoría que evoca los aspectos o las modalidades de la reproducción de "X": rostro, imagen, reflejo, espejo, eco, resonancia, estruendo, refracción, mutación.

5. Categoría centrada en la actitud de "Y": reacción, opinión, lectura, crítica, orientación» (Chevrel, 1994, pp. 148-187). 
El uso de la conjunción copulativa «y» o la preposición «en» implica una matización en la conceptualización del vínculo relacional entre los dos objetos, significando la primera «yuxtaposición» y la segunda «comprensión de un elemento en otro».

El PARALELISMO es un modo de relación que presenta una larga tradición (piénsese en las Vidas paralelas de Plutarco o el Parallèle des Anciens et des Modernes de Perrault) que concierne a otro esquema relacional clásico, el parangón (Silván, 2012, pp. 29-68). Otro término marcado es el de CORRESPONDENCIA, conceptualizado por Baudelaire en el ámbito poetológico y desarrollado ya en el siglo XX por Etienne Souriau en su ensayo La correspondencia de las artes (ed. esp. 1979).

A partir de los años 60 y 70 se ha divulgado el concepto de INTERTEXTUALIDAD, desarrollado sobre todo por Julia Kristeva (1966 y 1969) y Gérard Genette (ed. esp. 1989). Según Kristeva, todo texto se construye como mosaico de citas y es absorción y transformación de otro texto. Genette, por su parte, define el concepto de «transtextualidad» como todo aquello que pone al texto en relación, manifiesta o secreta, con otros textos, y distingue cinco diferentes tipos de relaciones transtextuales: la inter- / para- / meta- / hiper- y archi-textualidad.

De entre los teóricos del comparatismo, quizás sea Paul Van Tieghem el primero que sistematizó la terminología comparatista en La littérature comparée (Paris, Armand Colin, 1931). La segunda parte de este manual está dedicada a los «Métodos y resultados de la Literatura comparada». Van Tieghem determina tres elementos esenciales de la comunicación literaria, adoptando el esquema propio de la comunicación lingüística: el emisor, el receptor y el intermediario. Desde el punto de vista del emisor, estudiamos el succès, el éxito o fortuna; si nos situamos en el punto de vista del receptor, hablamos de «fuentes»; en cuanto al ámbito del intermediario, estudiamos el passage («Todo estudio de literatura comparada (...) tiene como objetivo la descripción de un passage», 1931, p. 68). Los intermediarios facilitan la difusión en un país y la adopción por parte de una literatura de obras, ideas y formas pertenecientes a otra. La rama de la Literatura comparada que estudia el intermediario se llamaría Mésologie (de mesos: «medios»). Intermediarios pueden ser actores sociales, individuos, periódicos y revistas, traductores $\mathrm{y}$ traducciones.

Según Van Tieghem, tras fijar las «fronteras» (que es decir, una vez establecidos los términos de comparación), ha de estudiarse todo lo que, bajo el dominio literario, ha pasado «d'un coté à l'autre». Es esta una acción que puede ser: (1) un enriquecimiento del espíritu por adquisición de conocimiento: (2) una modificación de la técnica por imitación de procedimientos artísticos; (3) una fermentación de ideas nuevas; (4) la simpatía con una sensibilidad que vibra al unísono con una sensibilidad extranjera (no han de olvidarse, desde luego, también las «antipatías» o rechazos).

El passage al que se refiere Van Tieghem es un hecho complejo, que implica diferentes elementos materiales y psicológicos. Así, el emprunt («prestamo») interesa entidades como: (1) los géneros literarios; (2) el estilo; (3) los sujetos (sujets), que pueden ser temas, tipos o leyendas; (4) las ideas o sentimientos.

Plantea seguidamente una taxonomía de los sujets; estos pueden ser: (1) thèmes: situaciones impersonales, los motivos tradicionales, los sujetos, lugares, cuadros, usos, etc.; (2) types: las profesiones, las actitudes, los caracteres de la «humanité moyenne», así como los seres ficticios o maravillosos que personifican ciertas tendencias del alma; (3) légendes: los acontecimientos o grupos de acontecimientos que tienen por actor ciertos héroes míticos, legendarios o históricos; héroes que ofrecen unos «échantillons d'humanité» únicos, determinados por la tradición en su carácter y actos principales. 
En cuanto a las ideas o sentimientos, distingue unas categorías principales: (1) ideas por las que la literatura es el modo de expresión pero no el objeto: es el caso de las ideas religiosas, filosóficas, morales; (2) ideas que tienen la literatura por objeto: son las propiamente estéticas y literarias (entran en estas categorías los «sentimientos»).

En el cap. 4 Van Tieghem describe las modalidades del intercambio literario. Establece diferentes concreciones relacionales y define varias cuestiones y problemáticas. En primer lugar, sugiere diferenciar influence (influencia) de succès (éxito).

- Según Van Tieghem, el Éxito, también llamado Fortuna, sería el objeto de estudio de una determinada subdisciplina, la «doxología» (de doxa, «opinión»). La extensión de la entidad a comparar puede ser variable (un escritor, un grupo de escritores o escuela, una literatura en su conjunto). El éxito puede ser de diferente naturaleza: (1) puede darse una acogida «simpática» y valoración positiva de crítica y conocedores; (2) una adopción por el publico letrado (especializado); (3) o una popularidad en el gran público. El éxito impulsa la «difusión». En el caso de grandes éxitos de público y de crítica, la biografía (tanto experiencial como intelectual) de un autor puede ser simplificada. El éxito provoca unos prestamos más amplios e imitaciones más extensas, y puede medirse también mediante las palabras o expresiones de un autor que han alcanzado un dominio público. La «difusión» de una obra puede ser bien directa (difusión del original en otro país), bien indirecta, es decir, a través de su traducción.

Según Pichois y Rousseau, «nacional e internacional, la fortuna es el conjunto de testimonios que manifiestan las virtudes aún vivas de una obra». El éxito se puede calcular cuantitativamente, mientras que la influencia es un fenómeno cualitativo: "si el éxito se calcula, la influencia se aprecia» (1969, p. 84). Un método para calcular la fortuna extranjera serían las traducciones. Según los dos comparatistas franceses, además, «la fortuna puede volverse desventura, y la influencia, resistencia» (p. 85). Weisstein (ed. esp. 1975, p. 180) está de acuerdo grosso modo con este planteamiento, mientras que Guyard (1957, pp. 24 y ss.) afirma que el estudio de la «fortuna» es un «género» propiamente francés.

- Influencia es término que significa un estado de cosas diferente respecto del éxito. Afirma Van Tieghem que ha de reservarse este nombre para las modificaciones que padece la obra de un escritor a contacto con la obra de otro escritor extranjero (p. 135). El interés de este fenómeno es tanto psicológico como literario. Tieghem apunta también una diferencia entre «influencia» $\mathrm{y}$ «semejanza» (ressemblances). $\mathrm{El}$ "punto de partida» es la cercanía de ciertos textos escritos por dos o más autores en los que las analogías dan lugar a una "presunción de influencia» (véase lo afirmado anteriormente). Dicha presunción puede darse por la forma o la idea y ha de presentar una evidencia mínima para excluir una afinidad azarosa o casual. Fundamentalmente, el texto extranjero debe ser conocido por el receptor.

La influencia puede ser establecida mediante la comparación de textos o por un análisis de los sentimientos, el estilo, etc., y es fundamentalmente parcial. No es totalmente cierto que un escritor está influido solo en la medida en que ya tenía esas mismas ideas latentes en su interior. Distingue diferentes géneros de influencia: (1) la figura moral e intelectual de un escritor; (2) la técnica; (3) la materia o sujets tratados por un escritor; (4) las ideas (ideología); (5) «nuevos dominios a explorar»: nuevos cadres, paisajes, entornos sociales, épocas, etc. Puede darse, además, una influencia negativa, que es lo que Escarpit define «traición creadora» (1960): se trata de la interpretación errónea de una determinada obra por parte del autor influido. 
Weisstein (1975, pp. 157-178), quien reseña en su análisis los principales estudios sobre el argumento publicados hasta entonces ${ }^{6}$, coincide finamente con la teoría de Ihab H. Hassan (1955): para Hassan la influencia no ha de entenderse como rapports de fait, sino como una red de coordenadas de correlaciones y similitudes múltiples que funcionan en una secuencia histórica, dentro de ese marco de supuestos que cada caso individual dictará.

Philippe Adrien Van Tieghem, escribió un ensayo sobre Les influences étrangères sur la Littérature Française (1550-1880) (1967). En él afirma que el sourcier quiere precisar el genio del escritor lo más cerca posible: lo despoja pues de toda aportación extranjera, llegando así al résidu auténtico que constituye su personalidad esencial. Al estudio de este «residuo» se dedican muy pocas obras, según el comparatista francés. Por otra parte, sostiene que el método consistente en mostrar, con la ayuda de los mismos prestamos, la originalidad del artista es más rentable. Cita entonces a Folkierski: «la originalidad de un artista se comprende a través de la manera con la que metamorfosea las fuentes». Así, lejos de ser una deviación de la dirección natural de un temperamento, la influencia padecida puede permitir a un temperamento latente y esencial de expandirse. También se ha afirmado que la influencia recibida del extranjero por parte de una literatura nacional no es sino la afirmación más expresiva de búsquedas perfectamente indígenas.

Alejandro Cioranescu, autor de un conocido L'Arioste en France (1938), no separa «fortuna» de «influencia», puesto que estas van naturalmente juntas. Recordemos que Cioranescu es autor de un interesante ensayo sobre Principios de literatura comparada $\left(2006,1^{a}\right.$ ed., p. 1964) ${ }^{7}$, el cual presente un breve apéndice titulado «Pequeño vocabulario comparatista». Allí define «influencia» como «subjetivación de uno o varios datos objetivos de una obra literaria anterior»; modelo: «obra literaria que ha dado lugar a una imitación»; e imitación: «repetición formalmente diferenciada de uno o varios aspectos de una obra literaria» (pp. 179-180).

El concepto de «influencia» ha tenido también críticas en el círculo de los comparatistas. Así Arturo Farinelli en el ensayo «Gli influssi letterari e l’insuperbire delle nazioni» (1972, pp. 271-290) asocia la manía casi patológica, propia de cierto comparatismo sobre todo francés, de enfatizar el descubrimiento de influencias a aspectos más bien políticos e ideológicos. Farinelli considera pues la comparatística centrada en la determinación de las influencias entre dos o más naciones como una especie de «juego de créditos y débitos» destinado a establecer la «superioridad» de una nación sobre la otra.

En la antecitada disertación de Wellek leída al segundo congreso internacional de la Asociación de Literatura Comparada (1959), el crítico checo plantea una crítica al concepto de influencia, porque lo ve como una herencia de cierto planteamiento positiva de la Literatura comparada. Ďurišin, por su parte, uno de los autores más relevantes del definido «nuevo paradigma», había eliminado la noción de influencia mediante la introducción de nuevos conceptos, como el de las «estrategias de integración» y de «diferenciación», y había atendido igualmente a las tensiones ideológicas y políticas que las inspiran. Es otro indicio de la evidente «sociologización» de la Literatura comparada en las últimas décadas del siglo XX.

6 Considera las obras de Ihab H. Hassan, Anna Balakian, Haskell Block, Claudio Guillén, Joseph T. Shaw y el número colectivo: The concept of Influence in Comparative Literature, en Comparative Literature Studies, University of Illinois, pp. 143-152.

7 Para una breve exposición sobre el comparatismo de Cioranescu, véase Lilica Voicu-Brey (2012, pp. 490-498). 
- La búsqueda de las FUENTES, operación crítica e historiográfica con una gran tradición, es el objeto, según Van Tieghem, de la Crénologie (de krene, fuente). El punto de partida es el receptor. Se distinguen unas (1) fuentes aisladas (serie sujetos/temas - detallas/motivos - ideas) y (2) otras colectivas (género, nación, literaturas plurinacionales, etc.). Mediante esta segunda tipología de fuentes se pretende determinar el conocimiento global de una literatura extranjera por parte de un autor.

«Fuente» es término plurisemántico y tiene diferentes significados según el ámbito en el que se considere. «Fuente histórica» describe un objeto diverso del de «fuente literaria». Sin embargo, los dos tipos de fuentes implican en su determinación un trabajo previo de investigación documental, empírica. La conocida como «crítica de las fuentes» se encarga de rastrear los modelos de los que un escritor se ha servido para realizar su obra. Metafóricamente, «fuente» alude a la «mecánica de los fluidos» por referirse a expresiones como «corrientes», «confluencias», etc. Por otra parte, cabe mencionar que la terminología de la Literatura comparada puede relacionarse también con la esfera lexical del lenguaje mercantil, por términos como "prestamo», «deuda», «aportación», «importación-exportación», etc., así como al filosófico-metafísico («unidad-multiplicidad», «monismo-pluralismo»: es la opción lexical de Claudio Guillén (2005), que no constituye en absoluto una novedad terminológica o conceptual, puesto que esas dualidades son las propias de la tradición hermenéutica).

La crítica de las fuentes, en su concreción decimonónica, se rige por un estricto causalismo. Este causalismo está guiado, en cierta medida, por el espejismo de la búsqueda del «origen». Cabe recordar que el término «origen» se explicita en los títulos de muchas de las investigaciones historiográficas del siglo XVIII: tómese como ejemplo más relevante la Historia Universal de las Letras y las Ciencias de Juan Andrés, titulada Origen, progresos y estado actual de toda la literatura. Puede considerase en cuanto anécdota esclarecedora de esta peculiar voluntad de investigar los orígenes de la humanidad y sus productos la exploración de James Bruce dirigida a buscar las fuentes del Nilo, de la que dejó testimonio en los volúmenes del Voyage aux sources du Nil (1790-1792, 14 vols.).

La investigación acerca de las fuentes implica un «movimiento» contrario (receptor $\rightarrow$ emisor) a la investigación sobre las influencias (emisor $\rightarrow$ receptor): «el rastreo de las influencias lleva de los emisores a los receptores. La de las fuentes, al contrario, va remontando la corriente y quizá exigen aún más tato y penetración crítica (...). El remontarse a las fuentes es una expedición por la oscuridad de lo posible» (Pichois y Rousseau, 1967, p. 90).

- La IMITACIÓN (imitatio) es operación literaria tradicional y se define como la emulación de los grandes escritores del pasado. La imitación es un acto intencional del escritor que toma como «modelo» a un autor «clásico» a fin de «competir» con él y «superarlo» (así, en el marco del parangón grecolatino, según los clasicistas Virgilio sería superior a Homero porque, imitándole, es autor de una obra más «perfecta»). La imitación literaria, concepto que deriva en parte de la mímesis aristotélica, condicionó toda la literatura europea hasta finales del siglo XVIII, cuando se dio el fin del clasicismo y el comienzo del movimiento prerromántico. Sería Kant quien conceptualizara la «originalidad», categoría que se podría entender como antinómica o complementaria a la de «imitación». El sucesivo movimiento romántico incidiría en la capacidad del «genio» creativo. Sin embargo, ya en el siglo XVII, con la conocida querelle entre Antiguos y Modernos, se asiste a una puesta en discusión del concepto tradicional de «imitación». 
El concepto de «imitación» en su sentido tradicional se relaciona, en la época moderna, con el de PLAGIO, concepto que presenta acepciones que sobrepasan los límites semánticos estrictamente literarios o estéticos, concerniendo pues aspectos más bien jurídicos. Croce habla del tema en un capítulo de sus Problemi di Estetica ( «Il plagio e la letteratura», ed. 1966), reseñando las obras de D. Giurati (Il plagio, 1903) y A. Lumbroso, Plagi, imitazioni e traduzioni (1902). Según el filósofo italiano, plagio es concepto que no tiene relación alguna con la literatura. Quien se adueña sin más de una obra ajena, no la altera en ningún aspecto. $\mathrm{Si}$, por el contrario, interviene con una serie de cambios o variaciones, la cuestión viene a ser si esas modificaciones son felices o menos, si la traducción es bella, la imitación oportuna, etc. En otro ensayo recogido en el mismo libro («La storia artística della Madonna»), Croce vuelve sobre la cuestión y escribe: «la repetición pura y simple no es posible sino en la copia, y en la copia material y mecánica. La copia, que interpreta, es ya otra obra de arte» (1966, p. 271).

Pichois y Rousseau, a propósito del fenómeno de la imitación, escriben que este

«se ha de separar del de la influencia. La influencia se experimenta de manera más o menos consciente: penetración lenta, ósmosis, o bien visitación, iluminación, no presenta carácter sistemático alguno, a diferencia de la imitación. Esta última linda por un lado con la sociología y por el otro con el derecho penal» (1967, p. 94).

- La RECEPCIÓn es concepto que se ha consolidado sobre todo a partir de los años 70 del siglo XX, desplazando el de «influencia» o «fortuna», y ello debido a la aparición de una corriente de la teoría y crítica de la literatura denominada Estética de la Recepción, cuyos principales teóricos son Hans Robert Jauss y Wolfgang Iser.

Weisstein dedica un largo apartado de su Introducción a la «Recepción y efecto» (1975, pp. 179-200); lo mismo hace Maria Moog-Grünewald en el capítulo «Investigación de las influencias y de la recepción» de la Teoría y praxis de la literatura comparada coordinada por Schmeling (1984, pp. 69-100). Pero quien hace un estudio conceptual más detenido de la «recepción» es sin duda Yves Chevrel en el Compendio de literatura comparada (1994, pp. 148-187).

Chevrel distingue entre los estudios sobre la influencia y recepción, precisando que estas son perspectivas de investigación diferentes y no necesariamente objetos de investigación diferentes: se trata, pues, de «modos» y no de «objetos». El planteamiento tradicional de la influencia «X e Y» no es una categoría 'cero', puesto que instaura una prioridad (se supone $\mathrm{X}$ superior a Y). Chevrel define los siguientes tipos de relación:

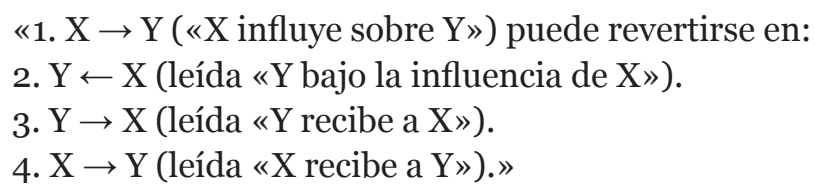

La relación 4 vuelve a ser igual que la fórmula 1, pero $\mathrm{X}$ pasa a ser el receptor e $\mathrm{Y}$ la fuente. Asistimos pues a una permutación de papeles de X e Y: en estos términos, el receptor es el que se toma como punto de partida, y ya no como punto de llegada; por lo tanto, la recepción no es considerada ya como algo pasivo. Se incide, pues, en el valor activo del término recepción. Concluye Chevrel que los estudios de recepción optan por hacer hincapié en la actividad del que recibe, más que en la actividad potencial del objeto recibido. 
En cuanto al método de la recepción y a su terminología, pueden distinguirse diferentes nociones clave. En primer lugar el «lector», que es el verdadero protagonista (así también en la Estética de la Recepción antemencionada). La «serie», puesto que el hecho literario nunca se concibe aislado. El «horizonte de espera», que puede ser del público o de la obra (es el concepto de «lector implícito»). El «sistema literario», tal y como lo hemos definido en el apartado anterior. Las «relaciones de sincronía y diacronía»: el estudio de la recepción puede constituirse también como investigación sincrónica. La necesaria «interdisciplinariedad», cuyo objetivo sería no encerrar lo literario en la literariedad.

\section{Conclusión}

En este artículo se han pretendido resumir, de manera incluso sinóptica, las principales propuestas metodológicas de la Literatura Comparada. Para ello se han tomado por centro, sobre todo y como no podía ser de otro modo, los planteamientos y evoluciones del último siglo, durante el cual la Literatura Comparada, una disciplina procedente de la antigüedad, traza un desarrollo universitariamente joven y altamente expansivo, en coincidencia, al menos en parte, con el crecimiento del sistema universitario estadounidense.

De añadir un elemento o factor de consideración posterior, este pensamos ha de ser el de las evoluciones, dominantemente anglosajonas, multiculturalistas, sociologizantes e ideologizadas cuyo avance en el campo académico de las Ciencias Humanas significa por principio la desintegración de la propia ciencia académica y su sistema educativo y disciplinar. Ésta es una importante cuestión pero que ahora no es nuestro objeto.

Desde un punto de vista estrictamente pedagógico, la Literatura Comparada ha de ofrecer al alumnado, en ámbito universitario, los instrumentos metodológicos esenciales para llevar a cabo una exégesis pertinente de textos intelectualmente complejos, entre otras cosas por entrecruzados con la Historia de las Ideas. Dada la casi total inexistencia de un complemento de las materias de Crítica en el plan de estudios de las diferentes titulaciones de letras o de filologías, la Teoría de la Literatura y Literatura Comparada ha de cubrir plenamente ese espacio. En estos términos, la metodología comparada aplicada a materiales literarios y filosóficos tiene su gran concreción pedagógica en el comentario de textos, fundamental para la didáctica en Ciencias Humanas ${ }^{8}$. Así, la metodología que hemos ilustrado en estas páginas se revela decisiva en cada una de las diferentes

8 En el marco de la asignatura de Teoría de la Literatura I de la Facultad de Filosofía y Letras de la Universidad de Alicante se están llevando a cabo desde hace algunos años unas prácticas docentes dirigidas a afianzar en el discente la capacidad de análisis de textos complejos de carácter teórico, habida cuenta de las carencias que el alumnado arrastra de su formación secundaria («Creación de un entorno digital docente para la asignatura de Teoría de la Literatura I: glosario de términos filológicos y certamen de comentario de texto en el ámbito de la Teoría literaria» -cód.: 4095-, PROGRAMA I3CE DE REDES DE INVESTIGACIÓN EN DOCENCIA UNIVERSITARIA de la Universidad de Alicante, desde 2017). Se trata de un proyecto didáctico de comentario de textos que, mediante una doble comparación (entre diferentes textos que versan sobre un mismo argumento y la sucesiva confrontación del comentario realizado con los de los demás alumnos del grupo de la asignatura), mira a la comprensión y consiguiente asimilación de conceptos teoréticos fundamentales para la disciplina en concreto y para el conocimiento enciclopédico en Ciencias Humanas en general. Uno de los principales criterios del proyecto consiste en centrar la lectura del texto, a diferencia de las usuales metodologías, que desvían la relación directa de lectura hacia un método interpuesto que anula la acción primordial que ha de permanecer de principio a fin como tal: la lectura o confrontación del sujeto con su objeto, siendo que este último es asimismo sujeto por cuanto habla al ser sometido a lectura. Consecuencia importante del procedimiento es promover la responsabilidad del sujeto lector, a su vez condición de toda libertad. 
fases del proceso de realización del comentario de textos, no ya artísticos, sino críticos y teóricos: la delimitación y definición del concepto, la comparación de facto o analógica entre textos u otros términos de comparación (obras artísticas, disciplinas, conceptos filosóficos, símbolos religiosos, etc.), con sus posibles dilucidaciones o descubrimientos, y las propuestas de síntesis conceptual conclusiva.

\section{Referencias bibliográficas}

Aldridge, O. (1969). Comparative Literature: Matter and Method. University of Illinois Press.

Aullón de Haro, P. (1992). Teoría del ensayo como categoría polémica y programática en el marco de un sistema global de géneros. Madrid: Verbum.

- (1997), «Introducción». En J. Andrés, Origen, progresos y estado actual de toda la literatura, vol. I. Madrid: Verbum.

-(2001). Teoría general del personaje. Madrid: Asociación Española de Eslavistas.

- (Ed.). (2012). Metodologías comparatistas y Literatura comparada. Madrid: Dykinson.

- (2016). Idea de la Literatura y Teoría de los géneros literarios, ed. de M.R. Martí Marco. Salamanca: Universidad de Salamanca.

Aullón de Haro, P., García Gabaldón, J., y Navarro Pastor, S. (Eds.). (2002). Juan Andrés y la teoría comparatista. Valencia: Generalitat Valenciana.

Backes, J.L. (1994). Poética comparada. En P. Brunel e Y. Chevrel (Eds.). Compendio de literatura comparada. (pp. 51-70). Madrid: Siglo XXI.

Beller, M. (1984). Tematología. En M. Schmeling, Teoría y praxis de la literatura comparada, (pp. 101-133). Madrid: Alfa.

Berger, W.R. (1984). Teoría de los géneros e investigación comparada de los géneros. En M. Schmeling, Teoría y praxis, cit. (pp. 135-168).

Cassirer, E. (1998). Filosofía de las formas simbólicas. 3 vols. México: FCE.

Chardin, P. (1994). Temática comparatista. En P. Brunel e Y. Chevrel, Compendio, cit. (pp.132-147).

Chevrel, Y. (1994). Los estudios de recepción. En P. Brunel eY. Chevrel (Eds.). Compendio, cit. (pp. 148-187).

- (1994). Problemas de una historiografía literaria comparatista: ¿es posible una 'historia comparada de las literaturas europeas'?. En P. Brunel e Y. Chevrel, cit. (pp. 347-373).

Chiapello, S. (2012). «Benedetto Croce y la primera cátedra de 'Literatura comparada'». En P. Aullón de Haro (Ed.), Metodologías comparatistas, cit. (pp. 463-477). 
Cioranescu, A. (2006), Principios de literatura comparada. Santa Cruz de Tenerife: Idea ( $2^{\mathrm{a}}$ ed.).

Croce, B. (1966). La letteratura comparata. En Id., Problemi di estetica e contributi alla Storia dell'estetica italiana. (6 $\left.{ }^{\mathrm{a}} \mathrm{ed}\right)$. Bari: Laterza.

Curtius, E. R. (2004). Literatura europea y Edad Media latina. 2 vols. México: FCE.

Debenedetti, G. (1970). Il personaggio-uomo. Milán: Il Saggiatore.

Didi-Huberman, G. (200). La imagen superviviente: historia del arte y tiempo de los fantasmas según Aby Warburg. Madrid: Abada Editores.

Dilthey, W. (1978). El mundo histórico, ed. de E. Ímaz. México: FCE.

Dionisio de Halicarnaso (2001). Sobre la composición literaria. Sobre Dinarco. Primera carta a Ameo. Carta a Pompeyo Gémino. Segunda carta a Ameo, ed. de G. Galán Vioque y M. A. Márquez Guerrero. Madrid: Gredos

Eliot, T. S. (1980). Traditional and the individual talent. En Id., Selected Essays (2 ${ }^{\mathrm{a}}$ ed.), (pp. 13-23). Londres: Faber \& Faber.

Escarpit, R. (1960). Sociologie de la littérature. París: PUF.

Even-Zohar, I. (1978). Papers in Historical Poetics. Tel Aviv: University Press.

Farinelli, A. (1972). Gli influssi letterari el'insuperbire delle nazioni. En Mélanges d'histoire littérarie générale et comparée offerts a Ferdinand Baldensperger. vol. I, (pp. 271290). Ginebra: Slatkine reprtints.

Fokkema, D.W. (1998). La literatura comparada y el nuevo paradigma. En Orientaciones en literatura comparada, ed. de D. Romero López. (pp. 149-172 ). Madrid: Arco/ Libros.

Gadamer, H.G. (1996-1998). Verdad y método. 2 vols. Salamanca: Sígueme.

Genette, G. (1989). Palimpsestos. La literatura en segundo grado. Madrid: Taurus.

Guillén, C. (2005). Entre lo uno y lo diverso. Introducción a la Literatura Comparada (Ayer y Hoy). Barcelona: Tusquets.

Guyard, M. F. (1957). La literatura comparada. Barcelona: Vergara.

Hassan, I. H. (1955). The problem of Influences in Literary History: Notes Towards a Definition. American Journal of Aesthetics and Art Criticism, 14.

Highet, G. (1954). La Tradición clásicas: influencias griegas y romanas en la literatura occidental. 2 vols. México: FCE.

Hobsbawm, E. y Ranger, T. (2002). La invención de la tradición. Barcelona: Crítica.

Jucquois, G. (1989). Le comparatisme. I. Genealogie d'une methode. Louvain-La-Neuve: Peeters.

- (1993). Le comparatisme. II. Émergence d'une méthode. Louvain-La-Neuve: Peeters. 
- (2000). Le Comparatisme dans les sciences de l'homme. Approches pluridisciplinaires. Bruxelas: De Boeck Universite.

Jucquois, G. y Swiggers, P. (1991). Le comparatisme devant le miroir. Louvain-LaNeuve: Peeters.

Jung, G. (1999). Sobre el fenómeno del espíritu en el arte y en la ciencia (Obra completa de Carl Gustav Jung, vol. 15), ed. de C. García Ohlrich. Madrid: Trotta.

Kristeva, J. (1966). Le mot, le dialogue et le roman. Critique, 239.

- (1969). Semiotiké. París: Seuil.

Maestro J. G. (2008). Idea, concepto y método de la Literatura comparada. Desde el Materialismo Filosófico como Teoría de la Literatura. Vigo: Academia del Hispanismo.

Marino, A. (1998). Histoire de l'idée de 'littérature européenne' et des études européennes. En B. Didier (Ed.). Précis de Littérature Européenne. París: PUF.

Mauz, A. y Von Saas, H. (Ed.). (2011). Hermeneutik des Vergleichs: Strukturen, Anwendungen Und Grenzen Komparativer Verfahren. Königshausen \& Neumann.

Moll, N. (2002). Imágenes del otro. La literatura y los estudios interculturales. En A. Gnisci, Introducción a la literatura comparada. (pp. 347-390). Barcelona: Crítica.

Moog-Grünewald, M. (1984). «Investigación de las influencias y de la recepción». En M. Schmeling, Teoría y praxis, .cit. (pp.69-100).

Nadler, J. (1984). El problema de la Historia del estilo. En. E. Ermatinger. Filosofía de la ciencia literaria, (pp. 401-425). México: FCE.

Pageaux, D. H. (1971). Images du Portugal dans les lettres françaises (1700-1755). París: Fond. Gulbenkian.

- (1994). La littérature générale et comparée. París: Armand Colin.

Panofsky, E. (1976). Estudios sobre iconología. Madrid: Alianza.

Pichois, C. y Rousseau, A. M. (1967). La literatura comparada. Madrid: Gredos.

Silván, A. (2012). Terminología originaria del compartismo. En P. Aullón de Haro, Metodologías comparatistas, cit. (pp. 29-68).

Souriau, E. (1979). Correspondencia de las artes. Elementos de estética comparada. México: FCE.

Swiggers, P. (1989). Signs, Structures and Systems in the Field of Literature. Semiotica, $75,345-352$.

- (1998). Innovación metodológica en el estudio comparativo de la literatura. En

Orientaciones en literatura comparada, cit. (pp. 139-148). 
Utrera, M.V. (2012). Métrica comparada. En Metodologías comparatistas, cit. (pp. 379394).

Van Tieghem, P. (1931). La littérature comparée. París: Armand Colin.

Van Tieghem, P. A. (1967). Les influences étrangères sur la Littérature Française (15501880). ( ${ }^{\mathrm{a}}$ ed.). París: PUF.

Voicu-Brey, L. (2012). La teoría comparatista de Alejandro Cioranescu. En Metodologías comparatistas, cit. (pp. 490-498).

Warburg, A. (2005). El renacimiento del paganismo. Aportaciones a la historia cultural del Renacimiento europeo. Madrid: Alianza.

- (2010). Atlas. Madrid: Akal.

Weisstein, U. (1975). Introducción a la Literatura Comparada. Barcelona: Planeta.

Wellek, R. (1968). Conceptos de crítica literaria. Caracas: Universidad Central de Venezuela.

Zymner, R. y Hölter, A. (2013). Handbuch Komparatistik. Theorien, Arbeitsfelder, Wissenspraxis. Stuttgart-Weimar: Verlag J.B. Metzler. 